\title{
Assessing skills development across the undergraduate degree programme: An IEP review - Biochemical Engineering
}

\author{
${ }^{1}$ Dr Mauryn C Nweke \\ ${ }^{1}$ Education, Practice and Society, Institute of Education, \\ University College London, London, UK \\ ${ }^{1}$ c.nweke@ucl.ac.uk
}

\begin{abstract}
Ensuring technical competency has traditionally been at the centre of engineering pedagogy in university education, however with ever more increasing emphasis on the need for professional skills by accreditation bodies and employers, there have been pressures on the education system to address this. Communication and teamwork competencies have been shown to be the most highly coveted by employers and in 2014, the Integrated Engineering Programme (IEP) at UCL was designed to address the inclusion of professional skills development in the curriculum in the first year of undergraduate studies. However, what is not clear is whether these skills are transferred into $2^{\text {nd }}$ and $3^{\text {rd }}$ year. This study investigated this by interviewing members of staff in Biochemical Engineering responsible for modules where these skills form part of the learning outcomes. The results indicate that whilst there is a general consensus that presentation skills are well developed, issues still arise in $2^{\text {nd }}$ and $3^{\text {rd }}$ year with teamwork skills and possible contributing factors could be related to a lack of awareness of suitable team formation strategies. Further findings included changes in students' perception of skills-based teaching as well as the need for sharing of best practice among IEP-related and non-IEP related staff alike.
\end{abstract}

Keywords: Skills in engineering education, communication, teamwork, Integrated Engineering Programme, Biochemical Engineering

\section{Introduction}

Over the past 20 years, advancements in societal activities such as the impact of technology on lifestyle choices and an ever-increasing population have led to increased demands on the healthcare system, the environment, food and energy supply, transportation and housing (Garrett, 2012; Johnson, 2020). During this time, the role of engineers has developed such that they are more closely linked with these societal changes and play a key role in high level decision making and creating solutions. It is therefore important that the type of engineer produced today is so-aligned, bringing into question whether or not education institutions globally are well-equipped to produce such engineers (Vohra, Kasuba and Vohra, 2006).

The need for broadening the curriculum has since been called to attention by a number of stakeholders including industry, professional institutions, government and accreditation bodies. All have highlighted the necessity for engineering education reform that allows for the attainment of a wider set of transversal skills, such as working in teams, thinking critically and creatively, taking into account socio-economic considerations, ethics and sustainability, all built on a deep technical foundation in order for engineers of today to be equipped to deal with societal and environmental changes (Perkins, 2013).

To address this, the UCL faculty of Engineering Sciences, that sees an average intake of over 1000 students per year, underwent a major revision of the engineering curriculum and in 2014 became the first high-ranking, research intensive UK university institution to successfully reform the curriculum across the majority of the faculty via the launch of the Integrated Engineering Programme (IEP) (John E Mitchell et al., 2019). On this programme, all students enter through their home departments but a common framework is shared that specifically integrates technical subject matter with professional skills, problem and project-based learning and design using a multidisciplinary and student-centred pedagogy in each stage of the students' degree (Tilley, Peters and Mitchell, 2014).

The programme consists of a number of modules taken in each year across a 3-year undergraduate degree programme. The foundation of the programme lies in the compulsory first year modules which are The Challenges, Design \& Professional Skills 1 (DPS1) and Mathematical Modelling and Analysis 1 (John E Mitchell et al., 2019).

The DPS1 module (which I manage at faculty level) is where students are trained on a number of skills within an engineering context including - creative and critical thinking, teamwork, project management, leadership and effective communication. In my role, I manage and coordinate $30+$ academic staff and $20+$ teaching assistants in various departments within the faculty to ensure the alignment of the skills and the discipline specific material within the syllabus, that the learning outcomes of the module are successfully delivered and adequate support is provided by the faculty. My interest in working in skills development on the IEP stemmed from being one of the first teaching assistant recruits on the programme in the year of its launch during my $\mathrm{PhD}$ studies. I had been extensively trained to assess and provide feedback to students in a range of skills including technical writing, presentations, teamwork, peer-assessment and project management. Since then I have led various parts of the module before becoming module lead for the faculty in 2017. 
One of the selling points of the IEP is the claim of attainment of transferable skills (John E Mitchell et al., 2019). The IEP has been running for 7 years and will see the graduation of 7 cohorts of students by the end of this academic year. However, something which is relatively understudied is whether the skills the students acquire in DPS1 are indeed transferred across their degree programme and if so, how well?

Understanding this will hopefully help me to review and develop my pedagogic practices, as well as those of other members of staff involved in delivering the module. It should provide insight into how these skills are applied throughout degree to make improvements to content and delivery and in addition, enhance staff community, dialogue and sharing of best practice.

As aforementioned, there are a number of skills taught on DPS1 and it would be beyond the scope of this enquiry to assess the transfer of each one. For that reason, two key skills have been selected for this enquiry. According to a report by Bloomberg, 2016 communication skills appear at the top of the list of what employers say they want from potential employees and coupled with the team based nature of working on engineering projects, both communication and teamworking skills appear to be arguably the most important skills to develop at an early stage (Seat, Parsons and Poppen, 2001; Lingard and Barkataki, 2011; Levy and Rodkin, 2016). There are 7 departments in the faculty whose students enrol onto DPS1, however it would be beyond the scope of this enquiry to assess the transfer of skills in each department. For that reason, the department of Biochemical Engineering (my home department) has been selected for this study. It is important to note however that future research should be done across the faculty to get a more holistic view of skills development on DPS1.

\section{Methodology - Enquiry approach}

There were a few approaches considered for this enquiry, particularly questionnaires and interviews. When deciding on which would be most appropriate, a number of factors were taken into consideration (see table 1). Whilst reviewing these factors, it was important to determine what type of information was needed in order to fulfil the aims of this enquiry, in other words, what type of information would a) aid in improving my pedagogic practice, b) aid in improving the pedagogic practice of staff involved in the module, c) provide in-depth information about how these skills are applied throughout the degree and d) help enhance staff community, dialogue and sharing of best practice. A further important factor that needed to be considered in order to determine the best approach was deciding on suitable people that could participate and provide information for this enquiry (Phellas, Bloch and Seale, 2011). Those mainly considered were students, alumni and staff. Staff were considered to be in a convenient position to provide a more holistic perspective, given they teach many students annually. Other factors considered were the time restraints for this study as well as the accessibility of the participants.
Table 1: A comparison of questionnaires and interviews as enquiry approaches (Surbhi, 2018)

The next step in deciding on the best approach was to consider which staff would be ideal participants. This involved investigating where presentation and teamwork skills were emphasised as learning objectives in other compulsory modules across the Biochemical Engineering undergraduate degree programme (flagship modules). I accessed this information via the Biochemical Engineering module catalogue and Moodle. From this search, I identified 3 colleagues who were responsible for $2^{\text {nd }}$ and $3^{\text {rd }}$ year flagship modules that were suitable for this study (UCL-Biochemical-Engineering, 2020).

Given the number of participants and the in-depth, analytical nature of the information being sought as well as other factors, interviews were deemed the most appropriate approach for this enquiry, specifically focus group interviews. The advantage focus group interviews have over other interview methods such as one-on-one interviews, is that it allows for discussion amongst participants, which provides data on how modules are connected, allows for staff dialogue and sharing of practice, which is in line with the aims of this enquiry (Nyumba et al., 2018). Using a semi-structured approach will allow me to cover particular themes, ask questions in different orders depending on the direction of the conversation and use unscripted questions to follow up on points of interest, whilst still allowing for open discussion amongst participants (Williams, 2015).

With that said, as the participants were colleagues of mine, issues concerning power relationships were to be considered. Upon receiving ethical approval for this research, I had taken steps to ensure that participants in my enquiry did not feel coerced to take part and that they were aware they may choose not to do so, with no adverse consequences. I am also aware that due to their awareness of my position in the faculty, participants may have felt they were required to provide 'correct answers' or answers that they believe I wanted to hear. I had assured participants in my enquiry of the value of their perspectives. Participants were provided with an opportunity to check that I had understood their contributions as they intended (for example, checking transcripts, engaging in a dialogue and checking understandings). Other ethical concerns including informed consent, confidentiality/anonymity and data protection have been accounted for by means of consent forms completed by the participants beforehand (see appendix), the use of pseudonyms in this research and the deletion of the focus group recording after its transcription. The 3 participants were given gender-neutral pseudonyms - Alex, Jay and Sam.

The approach towards the types of questions asked was to ensure the focus of the enquiry remained intact but also to encourage discussion among the module leads. The

\begin{tabular}{|l|l|l|}
\hline Comparison & Questionnaire & Interview \\
\hline $\begin{array}{l}\text { Quantity of } \\
\text { participants }\end{array}$ & $\begin{array}{l}\text { Often } \\
\text { numbers }\end{array}$ & $\begin{array}{l}\text { Often small } \\
\text { numbers }\end{array}$ \\
\hline Questions of & Closed Ended & Open Ended \\
\hline $\begin{array}{l}\text { Type } \\
\text { information }\end{array}$ & Analytical \\
\hline Question order & Cannot be changed & $\begin{array}{l}\text { Can be changed } \\
\text { as needed }\end{array}$ \\
\hline Reachability & One to many & One to one \\
\hline $\begin{array}{l}\text { Likely response } \\
\text { rate }\end{array}$ & Low & High \\
\hline
\end{tabular}


discussion was geared towards understanding how teamwork and presentations were used in their respective

modules, separately or/and concurrently, what developments staff have seen in these skills after $1^{\text {st }}$ year (good aspects as well as challenges), how the perception of the need for these skills changes as the students complete their degree and what improvements can be made from first year that would benefit their $2^{\text {nd }}$ year and $3^{\text {rd }}$ year modules. The focus group took place in term 3 (mid-April) online via Microsoft Teams due to the COVID-19 pandemic.

As this was a qualitative piece of research, findings were analysed using a thematic approach. This method of data analysis involves identifying patterns of themes raised in the interview data. The six steps taken to analyse the data were based on methodologies reported in Nowell et al., 2017 and Caufield, 2019. These sources indicate that after familiarising yourself with the data, subsequent steps involve identifying re-occurring themes and defining them. This involves making notes and annotations regarding development and hierarchies of concepts in the raw data. Subsequently, the final step involves providing rationale for the analytical choices made in data interpretation, which should link back to the interview schedule as well as the aims of the study.

\section{Findings and discussion}

The findings of this study were based around staff observations of the development of teamwork and presentation skills throughout the Biochemical Engineering undergraduate degree programme. A vast number of themes were identified, however 3 key themes were selected based on how much they were emphasised among all participants. Of these 3 themes, one is related to teamworking skills (team formation strategies), one is related to presentation skills (different types of presentations) and the last theme is in relation to students' perception of skills teaching on the IEP.

\subsection{Teamwork}

The ability to work in teams in engineering is considered to be a necessity by employers and this has contributed towards it being one of the main learning outcomes on DPS1. However what is not well understood is whether the skills and practice obtained in DPS1 has adequately prepared students for working in teams in other contexts in years 2 and 3 of their studies. Studies have shown that team dynamics play a key role in determining how well a team works together (Gelbard and Carmeli, 2009). However, the dynamics of a team is very much dependent on who the members are and how the teams are formed (Ercan and Khan, 2017). A theme raised by all participants concerned inconsistencies in team formation strategies across the degree programme:

Alex: "In my scenario, I let them pick their own teams, so it's the only scenario where they pick their own group members."

Sam: "I always try to ensure a male-female balance within the groups as much as possible and sometimes the groups are balanced in terms of having a strong, medium and poor person in them, and sometimes I've grouped them so that they are by grade so that the stronger ones are together and the poorer ones are together."

Studies have reported on the benefits and disadvantages of the use of faculty-assigned teams (teams assigned by staff) and self-selection (student-selected teams). While self-selection allows for students to work with peers they get on with, faculty-assigned teams are generally considered more appropriate, fair and representative of industry as it can intentionally take into account factors such as gender, academic performance, ethnicity, among others (Adams, 2003).

Another team formation strategy used on the IEP is based on personality tests. In this strategy, students fill out a questionnaire prior to the team activity in order to determine what their strengths are. The one used on the IEP is the Clifton Strengths for students and this allows students to identify themselves as leaders, executers, mediators, amongst other traits. Based on this, teams can be formed to ensure a mix of capabilities (John E. Mitchell et al., 2019). Whilst this has proved beneficial when used by employers as a positive psychological tool, there have been concerns about using this strategy as a sole method for team forming (Rhee, Parent and Basu, 2013).

Whilst there is no consensus in literature concerning the best method for team formation, it is important to ensure that information of different team forming strategies is shared with all members of staff, irrespective of whether they are IEP-related. That way, staff across all modules in the degree programme will be able to use their discretion to apply the most suitable strategy depending on the activity type, team size, as well as other factors, which is reflective of what is done in industry (Adams, 2003).

\subsection{Presentations}

Communication is considered to be one of the most coveted professional skills by employers (Levy and Rodkin, 2016). In engineering, presentations are one of the most common practices of verbal communication in the workplace and participants in this study generally agreed that presentation skills are well developed in DPS1 and the transfer of this skill is seen across the degree programme: Jay: What I have noticed in general is that the quality of presentations has gone up over the past 3 or 4 years, I don't know if you agree Sam? We used to get the occasional very flaky presentation in design, maybe 5 years ago. I remember a couple of ones where they didn't take it seriously at all ... but in general now they're all pretty professional and pretty much keep to tight time constraints we give them and get their message over fairly well. Obviously there are exceptions to that but the general standard has improved.

With that said, there a number of different types of presentations employed in this sector (Dannels, 2003). A theme raised in relation to this was the underpreparedness of students for non-powerpoint presentations:

Sam: " In terms of presentations, each team has to do 2 presentations a term, 2 oral presentations as a team and 
then there are also 2 poster presentations at the end of each part."

Alex: "Yes poster based. So on the Thursday I go through some examples from the graduate school competition because they really don't know how to make a poster. They think they know but they don't really know."

Whilst powerpoint presentations are the most popular used across a number of sectors, including engineering, other common presentation styles in engineering include poster presentations, pitch presentations, demopresentations, showcase presentations, among others (Dannels, 2003). Whilst some of these presentation types are covered elsewhere on the IEP, it may be worthwhile considering the possibility of incorporating at least one other presentation type in the DPS 1 curriculum, particularly poster presentations, as it is present across the Biochemical Engineering degree programme. It is important to note however that further studies will need to be done cross faculty to ascertain whether poster presentations are as prevalent in other departments. This will help to determine the feasibility of its implementation in the DPS1 curriculum as a whole.

\subsection{General perceptions}

The implementation of skills-based teaching has meant a change to pedagogical practice across the faculty. This has been met with some resistance from the traditionalists that promote a more solely technical-focused pedagogy (John E Mitchell et al., 2019). As a result, as students begin their degree programme within their departments and consequently come across the IEP, they are often taken aback by the differing approach to teaching and their thoughts on this are often reflected in the annual student evaluation questionnaires (SEQs), taken after the first term of DPS1. One of the aims of this study was to find out whether the general student perception is maintained throughout their degree programme or whether it changes. The participants were asked about this and their responses were generally reflected by the view stated below:

Alex: "I think it's hard because when you ask the students as a cohort, they can often be quite negative about the IEP, but when you ask them when it comes to writing their reference letters and things like that, they're enormously appreciative of the skills that they get on the IEP and the way that you get lots of things to talk about that are original."

Studies have shown that one of the main difficulties in skills teaching to groups that have not previously worked professionally is dealing with perception (Lizzio, Wilson and Simons, 2010). Whilst this continues to be a challenge on the IEP, steps have been put in place to help students understand its importance in their $1^{\text {st }}$ year of studies, based on past SEQ data and research. One of these measures includes the use of student ambassadors (Tariq, 2018). These are usually $2^{\text {nd }}$ and $3^{\text {rd }}$ year students who are able to relate to $1^{\text {st }}$ year students and inform them of how these skills will be beneficial in subsequent years of study as well as for internships and employment. The DPS1 SEQs have shown a positive impact as a result of this measure. However, although its impact remains gradual, sharing of this practice among colleagues could prove beneficial for perceptions of future students and possibly traditionalist staff alike.

\section{Conclusion}

The findings from this study indicate that from the perspective of those in the Biochemical Engineering department at least, there are a number of positive outcomes by the introduction of the IEP and within that, DPS1. These include the general agreement that presentation skills are well developed and transferred to $2^{\text {nd }}$ and $3^{\text {rd }}$ year of studies, along with the improvement in the perception of the IEP and the advantages of skills acquired as students advance in the degree programme. However, where there is most room for improvement concerns teamwork skills. The findings show that there are inconsistencies in creating teams which may be down to a lack of awareness of the most suitable team formation strategy in any given year. This finding can be used to help improve my practice in a number of ways, the most clear being creating a platform by which IEP-related and nonIEP related staff have access to resources about different team forming strategies that they can then use to help decide the most suitable approach.

It is important to note that the results are not conclusive of the overall influence of DPS1 as similar studies in other departments across the faculty would need to be done. It does however provide a foundation upon which ideas for further enhancements can be made. If skills transfer across a degree programme can be shown, it is likely that they are successfully transferred into employment also. However how these skills are adapted in the working environment would make for an informative future study, which could feedback into how skills education on the IEP could help prepare students for working professionally.

\section{Acknowledgements}

This work gladly acknowledges the department of Education, Practice and Society, IOE, UCL. The author wishes to thank supervisors Dr Lynne Rogers and Dr Abel Nyamapfene.

\section{References}

Adams, S. (2003) 'Building Successful Student Teams in the Engineering Classroom', Journal of STEM Education, 4(July), pp. 1-6.

Caufield, J. (2019) How to do thematic analysis, Scribbr Methodology. Available at: https://www.scribbr.com/methodology/thematic-analysis/ (Accessed: 7 May 2020).

Dannels, D. (2003) 'Teaching and Learning Design Presentations in Engineering: Contradictions between Academic and Workplace Activity Systems', Journal of Business and Technical Communication, 17(2), pp. 1-7. doi: 


\section{$10.1177 / 1050651902250946$.}

Ercan, F. and Khan, R. (2017) 'Teamwork as a fundamental skill for engineering students', in IEEE 6th International Conference on Teaching, Assessment and Learning for Engineering (TALE), pp. 1-3. doi: 10.1109/TALE.2017.8252298.

Garrett, B. M. (2012) 'Nurse Education in Practice Changing the game; some thoughts on future healthcare demands, technology, nursing and interprofessional education', Nurse Education in Practice. Elsevier Ltd, 12(4), pp. 179-181. doi: 10.1016/j.nepr.2012.03.006.

Gelbard, R. and Carmeli, A. (2009) 'The interactive effect of team dynamics and organizational support on ICT project success', International Journal of Project Management. Elsevier Ltd and IPMA, 27(5), pp. 464-470. doi: 10.1016/j.ijproman.2008.07.005.

Johnson, J. (2020) 'Negative effects of technology: what to know', Medical News Today, 20-21(12).

Levy, F. and Rodkin, J. (2016) The Skills Gap, The Bloomberg Job Skills Report. Available at: https://www.bloomberg.com/graphics/2016-job-skillsreport/ (Accessed: 4 May 2020).

Lingard, R. and Barkataki, S. (2011) 'Teaching Teamwork in Engineering and Computer Science', Frontiers in Education Conference (FIE). IEEE, 8(2010). doi: 10.1109/FIE.2011.6143000.

Lizzio, A. L. F., Wilson, K. and Simons, R. (2010) 'Studies in Higher Education and Academic Outcomes: University Students 'Perceptions of the Learning Environment and Academic Outcomes : implications for theory and practice', Studies in Higher Education, 5079(June 2012), pp. 37-41. doi: 10.1080/0307507012009935.

Mitchell, John E et al. (2019) 'Faculty wide curriculum reform: the integrated engineering programme programme', European Journal of Engineering Education. Taylor \& Francis, $0(0), \quad$ pp. 1-19. doi: 10.1080/03043797.2019.1593324.

Mitchell, John E. et al. (2019) 'Faculty wide curriculum reform: the integrated engineering programme', European Journal of Engineering Education. Taylor \& Francis, 0(0), pp. 1-19. doi: 10.1080/03043797.2019.1593324.

Nowell, L. S. et al. (2017) 'Thematic Analysis : Striving to Meet the Trustworthiness Criteria', International Journal of Qualitative Methods, 16, pp. 1-13. doi: 10.1177/1609406917733847.

Nyumba, T. O. et al. (2018) 'The use of focus group discussion methodology: Insights from two decades of application in conservation', Methods in Ecology and Evolution, 2018(July 2017), pp. 20-32. doi: 10.1111/2041210X.12860.

Perkins, J. (2013) Engineering skills for the future, Royal Academy of Engineering. Available at: https://www.raeng.org.uk/publications/reports/engineeringskills-for-the-future (Accessed: 5 April 2020).

Phellas, C. N., Bloch, A. and Seale, C. (2011) STRUCTURED METHODS : INTERVIEWS , QUESTIONNAIRES AND OBSERVATION, Sage Publications.

Rhee, J., Parent, D. and Basu, A. (2013) 'The influence of personality and ability on undergraduate teamwork and team performance', SpringerPlus, 2(1), pp. 1-14. doi: 10.1186/2193-1801-2-16.

Seat, E., Parsons, R. and Poppen, W. (2001) 'Enabling Engineering Performance Skills: A Program to Teach Communication , Leadership , and Teamwork', Journal of Engineering Education, 14(January), pp. 7-12.

Surbhi, S. (2018) Difference Between Questionnaire and Interview, Key Differences. Available at: https://keydifferences.com/difference-betweenquestionnaire-and-interview.html (Accessed: 6 May 2020).

Tariq, A. (2018) Student Ambassadors: Working and how they influence others. Tampere University of Applied Sciences. Available at: https://core.ac.uk/download/pdf/161424315.pdf.

Tilley, E., Peters, J. and Mitchell, J. (2014) 'Teaching selfawareness, diversity and reflection to support an integrated engineering curriculum augmented with problem and scenario-based learning . Conference Topic: Active Learning New Criteria for Engineering Graduates UCL TEACHES ENGINEERING DESIGN', in SEFI 42nd Annual Conference, Birmingham, UK, pp. 1-7.

UCL-Biochemical-Engineering (2020) Engineering (Biochemical) MEng, UCL.ac.uk. Available at: https://www.ucl.ac.uk/biochemical-

engineering/study/undergraduate/engineering-biochemicalmeng (Accessed: 5 May 2020).

Vohra, P., Kasuba, R. and Vohra, D. P. (2006) 'Preparing Engineers for a Global Workforce through Curricular Reform', Global Journal of Engineering Education, 10(2). Williams, A. (2015) Conducting Semi-Structured Interviews, Research Gate. doi: 10.1002/9781119171386.ch19. 